Universidad de Lima

Facultad de Ciencias Empresariales y Económicas

Carrera de Administración

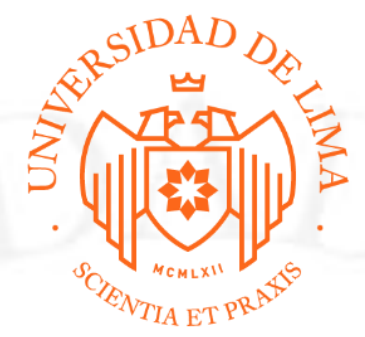

\title{
SUSTENTACIÓN DE CASO: PROPUESTA DE UN PLAN ESTRATÉGICO DEL INGRESO AL MERCADO PERUANO DE UNA EMPRESA DEL SECTOR FAST FASHION
}

Trabajo de suficiencia profesional para optar el Título Profesional de Licenciado en Administración

Javier Fernando Taboada Villanueva

Código 20113091

$$
\text { Lima - Perú }
$$

Noviembre del 2018 


\section{SUSTENTACIÓN DE CASO: PROPUESTA DE UN PLAN ESTRATÉGICO DEL INGRESO AL MERCADO PERUANO DE UNA EMPRESA DEL SECTOR FAST FASHION}




\section{TABLA DE CONTENIDO}

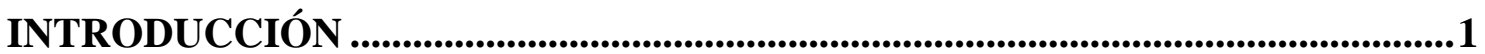

CAPÍTULO I: DIAGNOSTICO ESTRATÉGICO ...............................................2

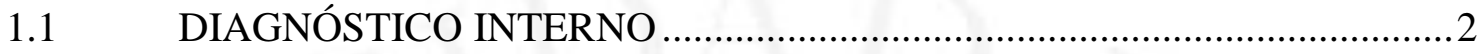

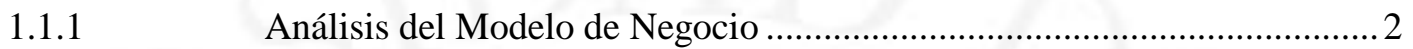

1.1.2 Análisis de la Cadena de Valor ................................................................. 3

1.1.3 Definición y sustentación de las ventajas competitivas de la empresa y por UEN (Unidad Estratégica de Negocios) ..........................................................................

1.1.4 Determinación y sustentación de las Fortalezas y Debilidades de la empresa y por UEN (Unidad Estratégica de Negocios) ....................................................... 9

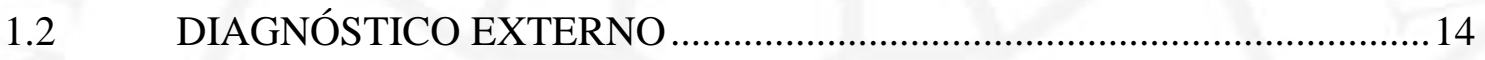

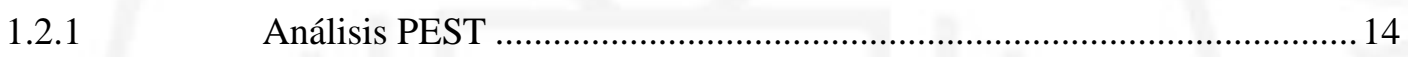

1.2.2 Análisis de las fuerzas competitivas del sector industrial ........................16

1.2.3 Determinación y sustentación de las Oportunidades y Amenazas .............18

CAPÍTULO II: FORMULACIÓN DE LA ESTRATEGIA ........................................20

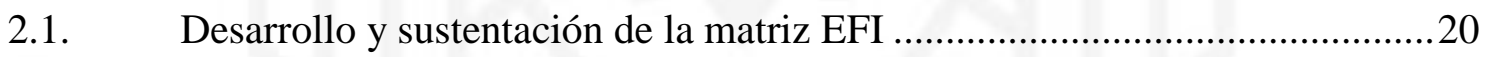

2.2. Desarrollo y sustentación de la Matriz EFE.................................................2 21

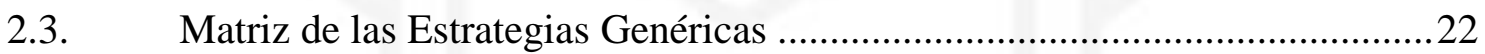

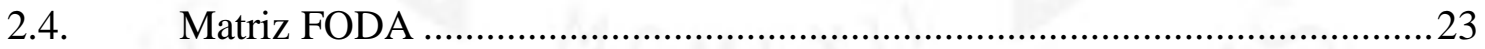

2.5. Definición y sustentación de la Visión, Misión y Políticas............................25

2.6. Definición de los Objetivos Estratégicos de la Empresa...............................27

2.7. Redefinición de las UEN (Unidad Estratégica de Negocios) o

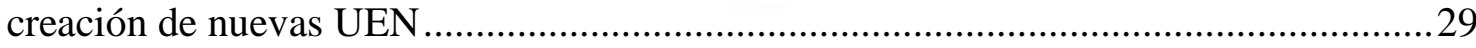

2.8. Propuesta y sustentación de Estrategias en el ambiente Global,

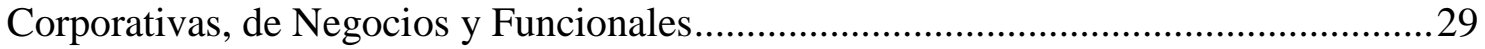

CAPÍTULO III: IMPLEMENTACIÓN ESTRATÉGICA..........................................33 
3.1 Evaluación del rediseño o no rediseño de la estructura organizacional de la empresa

3.2 Propuesta de cambios para mejorar la implementación de estrategias en la empresa

CAPÍTULO IV: CONTROL ESTRATÉGICO ..........................................................36

4.1 Diseño de un Mapa Estratégico de Control para la empresa..........................36

4.2 Desarrollo de un Cuadro de Mando Integral con un mínimo de 10 índices de gestión

CONCLUSIONES .40

RECOMENDACIONES .41

REFERENCIAS BIBLIOGRAFICAS 42 


\section{ÍNDICE DE TABLAS}

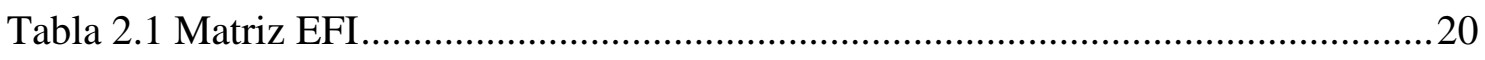

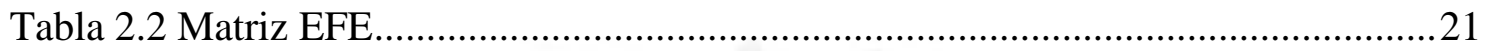

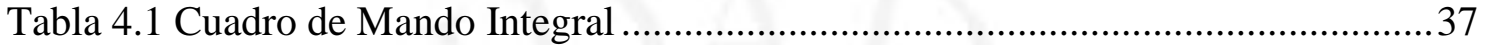




\section{ÍNDICE DE FIGURAS}

Figura 1.1 Modelo Canvas: Fast Retailing ...........................................................2

Figura 1.2 Cadena de valor: Fast Retailing ..........................................................

Figura 1.3 Elementos básicos de la ventaja competitiva ............................................6

Figura 1.4 Resultados de la encuesta de satisfacción al cliente (UNIQLO) .................... 8

Figura 2.1 Matriz de las Estrategias Genéricas.............................................................22

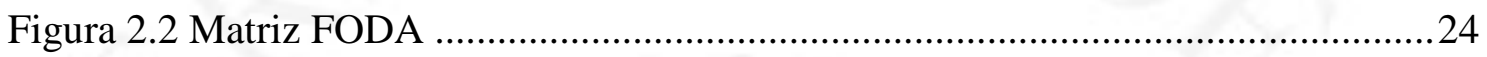

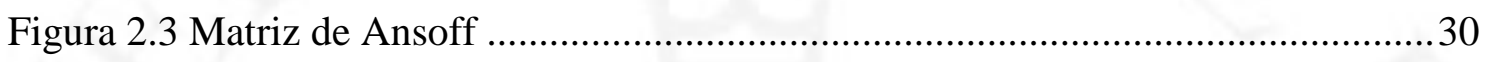

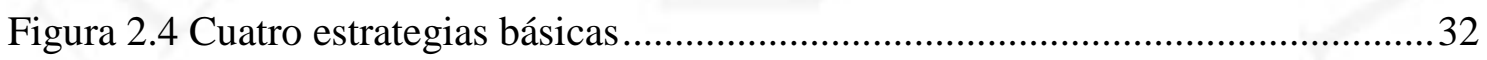

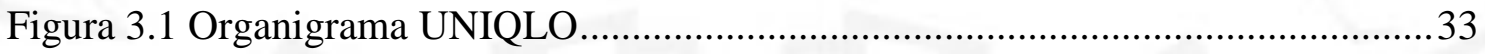

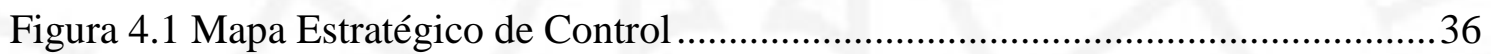




\section{INTRODUCCIÓN}

El trabajo de investigación que se presenta a continuación está basado en el desarrollo del caso "Las industrias de la moda rápida y el futuro de Fast Retailing en el mercado peruano" de la Universidad de Lima. Éste, tiene como objetivo realizar un análisis empresarial de la compañía y desarrollar un plan estratégico que facilite su ingreso al mercado nacional.

El Grupo Fast Retailing (FR) inicia sus operaciones en Japón en el año 1984 con la apertura de su primera tienda UNIQLO, ésta es su marca emblema y posee 2042 establecimientos a nivel mundial. Adicional a esta marca, FR también maneja GU, la cual es su segunda marca más grande y cuenta con 392 tiendas; así como, también, Theory, Comptoir des Cotonniers, Princesse tam.tam y J Brand enfocadas en distintos mercados y ofrecen variedad de tipos de productos textiles.

Fast Retailing tiene como objetivo para el 2019 ingresar al mercado peruano por lo que se evaluarán factores como la industria Fast Fashion en la actualidad y como se ha venido desarrollando este innovador modelo de negocio desde la llegada a nuestro país en el año 2012 con el ingreso de Zara, seguido de H\&M y Forever 21. Se analizarán las fortalezas, oportunidades, debilidades y amenazas para elaborar estrategias que se sustenten en base a las ventajas competitivas que tiene la empresa y a sus objetivos.

Se fundamentarán los análisis, las estrategias y los objetivos planteados sobre la base de los artículos relacionados a la industria fast fashion, el caso "Grupo Fast Retailing" publicado por la Universidad Harvard Business School e información adicional que ha sido recolectada de libros e internet. 


\section{CAPÍTULO I: DIAGNOSTICO ESTRATÉGICO}

\subsection{DIAGNÓSTICO INTERNO}

\subsubsection{Análisis del Modelo de Negocio}

Para el análisis del modelo de negocio que viene aplicando Fast Retailing, se utilizará una herramienta llamada Modelo Canvas, el cual permitirá analizar 9 bloques principales del desarrollo del negocio: Asociaciones claves, actividades clave, recursos clave, estructura de costos, propuesta de valor, relación con los clientes, canales, segmentos del mercado y fuentes de ingreso.

Figura 1.1

Modelo Canvas: Fast Retailing

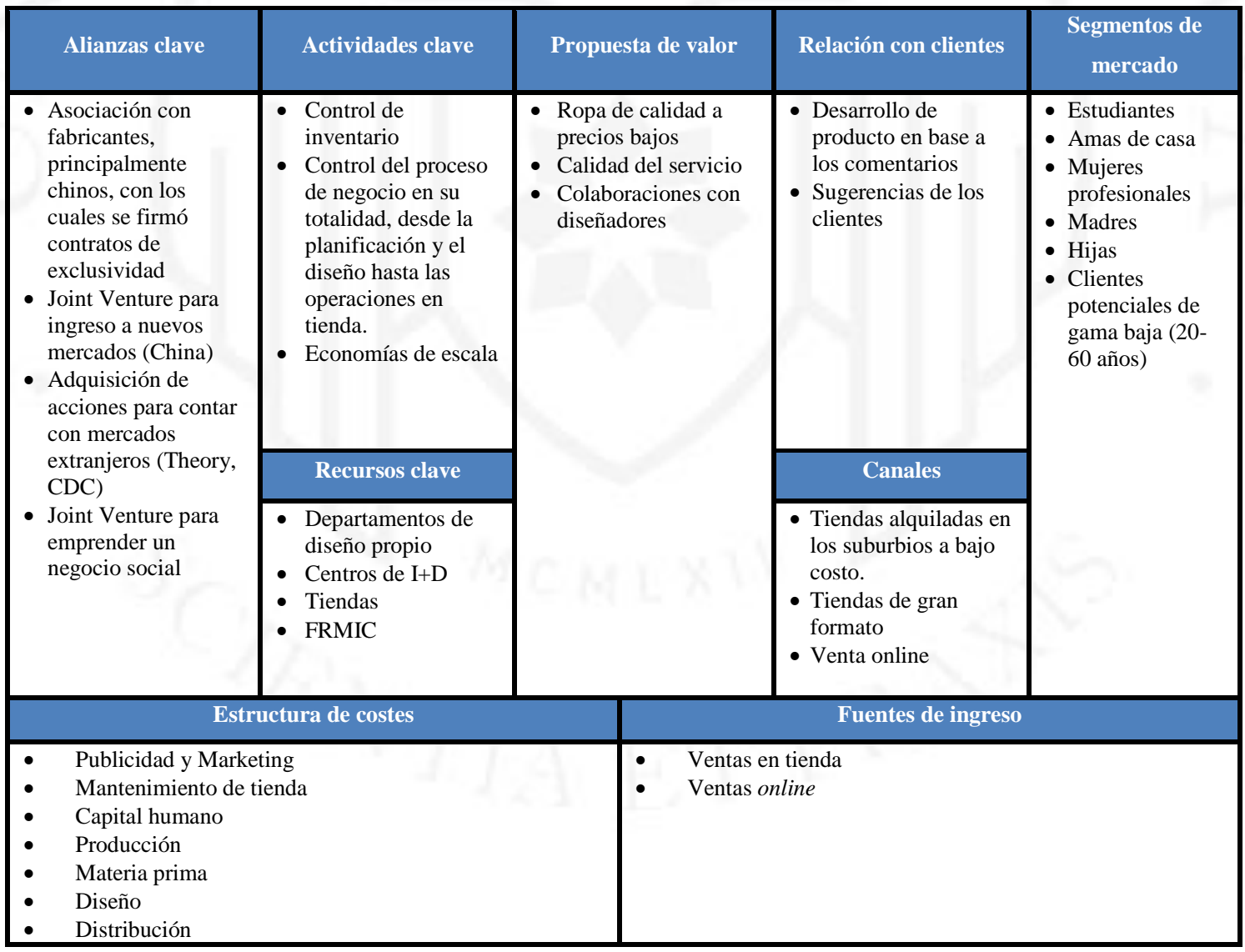

Fuente: Ismail, S., Malone, M. S., y van Geest, Y. (2016).

Elaboración propia 


\subsubsection{Análisis de la Cadena de Valor}

A continuación, se desarrollará la Cadena de Valor del grupo Fast Retailing considerando las actividades primarias y las de apoyo.

\section{Figura 1.2}

Cadena de valor: Fast Retailing

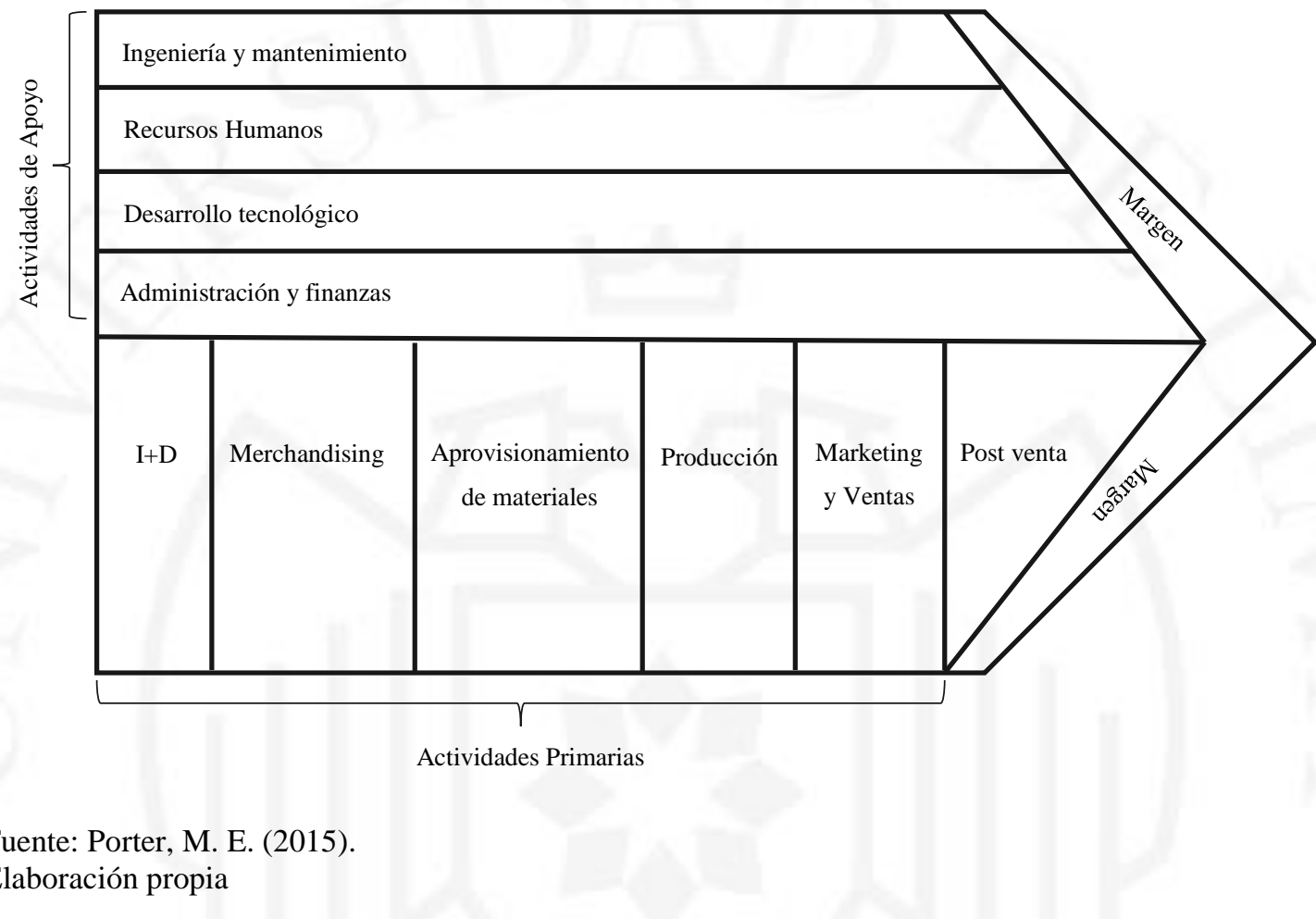

\section{Investigación y Desarrollo}

El departamento de Investigación \& Desarrollo (I+D) se encuentra en la constante búsqueda de las nuevas tendencias de la moda y estilos de vida alrededor del mundo. Asimismo, se sostienen reuniones con las áreas de Merchandising, Marketing, Ventas, Desarrollo de Producto y Producción aproximadamente con un año de anticipación antes de sacar al mercado los nuevos diseños.

\section{Merchandising}

Después de reunirse con el equipo de I+D, el área de Merchandising se encarga de implementar todos los conceptos de diseño a los planes de producción, así como de verificar los materiales que se usarán. Adicionalmente, también determinan el volumen 
de producción para cada temporada y deciden en qué momento aumentar o disminuir la misma, considerando la estrategia de marketing a ser aplicada y la demanda del mercado.

\section{Aprovisionamiento de materiales}

FR adquiere insumos de distintas partes del mundo, buscando conseguir materiales de buena calidad a precios bajos; y lograr economías de escala adquiriendo volúmenes grandes de materia prima.

\section{Producción}

La empresa cuenta con un departamento de Producción que se encarga de supervisar las producciones que se llevan a cabo en las fábricas de los proveedores con los cuales sostienen contratos de exclusividad para que la ropa cumpla con los estándares de calidad que maneja la compañía, y así puedan detectar oportunidades de mejora. La mayor parte de estas fábricas se encuentran en China.

\section{Marketing}

El grupo se encarga de promocionar sus productos en medios de comunicación tradicionales y nuevo. Por ejemplo, utiliza las inserciones en los periódicos para promover las promociones de sus productos, así como también lo hace en $\mathrm{TV}$, redes sociales y su página web.

\section{Venta}

La compañía tiene dos canales de venta: mediante sus tiendas físicas, las cuales fueron 3294 en el 2017, y por la venta online.

\section{Post venta}

En el caso de UNIQLO, la principal marca del grupo cuenta con un centro de atención al cliente, servicio post venta que recolecta alrededor de 70000 opiniones y solicitudes las cuales toman en consideración para el desarrollo de producto, tiendas y servicios.

\section{Infraestructura e Ingeniería}

Encargados del proceso de construcción y mantenimiento de las tiendas a nivel global. 


\section{Recursos Humanos}

El área de Recursos Humanos es la encargada de los procesos de selección del personal, capacitaciones, medir la satisfacción laboral, desarrollar actividades para mejorar el clima, entre otros.

\section{Tecnología}

Con las innovaciones que se van presentando día a día, el área de Tecnología es un elemento fundamental en la empresa. Ésta se encarga de analizar la posibilidad de implementar las nuevas innovaciones referentes a procesos y productos tecnológicos, verificar que todos los sistemas de la empresa funcionen correctamente, especialmente el de las tiendas, entre otras.

\section{Administración y Finanzas}

Esta área se encarga del planeamiento financiero y de algunos procesos estratégicos como la formulación anual del presupuesto, administración de contratos, contabilidad, tesorería y cobranzas.

\subsubsection{Definición y sustentación de las ventajas competitivas de la empresa y por UEN (Unidad Estratégica de Negocios)}

Para identificar las ventajas competitivas de la empresa y de las UEN, se desarrollarán de los elementos básicos de la ventaja competitiva. 


\section{Figura 1.3}

Elementos básicos de la ventaja competitiva

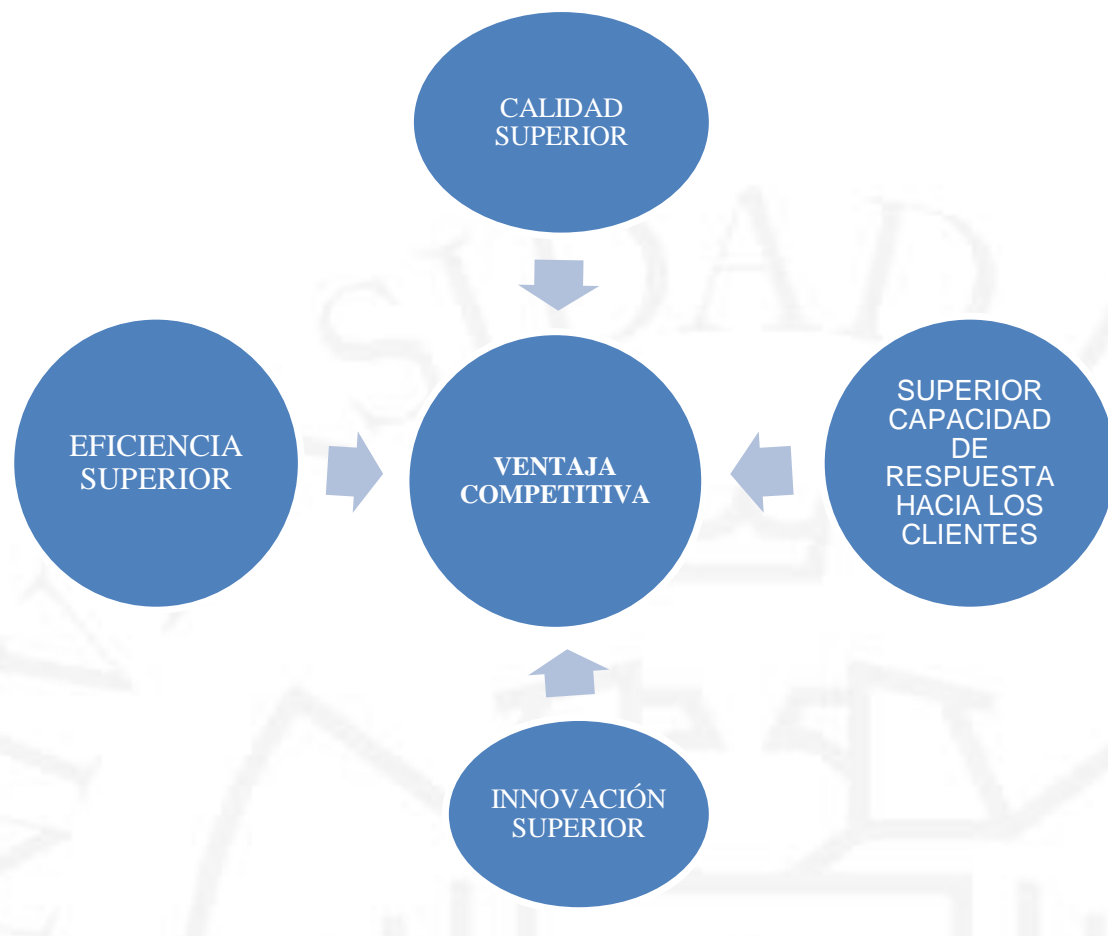

Fuente: Hill, C. W. L. y Jones, G. R. (2009).

Elaboración propia

Las ventajas competitivas del grupo Fast Retailing son las siguientes:

\section{EFICIENCIA SUPERIOR}

Esta ventaja competitiva representa la capacidad de FR de ofrecer productos a bajo precio y de buena calidad enfocándose en mantener sus costos bajos. La compañía ha desarrollado la habilidad de lograr economías de escala, adquiriendo grandes volúmenes de materia prima para el desarrollo final de las prendas que comercializan en distintos países del mundo.

\section{SUPERIOR CAPACIDAD DE SATISFACCIÓN AL CLIENTE}

Lo que busca FR es que sus clientes sientan sensaciones positivas a la hora de utilizar sus prendas. Esto demuestra el enfoque que la compañía tiene hacia el cliente, dándoles la oportunidad a las personas de usar prendas a precios bajos y que se encuentran dentro de las tendencias de la moda.

Adicionalmente, el grupo maneja variedad de marcas para los diferentes segmentos de mercado; por ejemplo, cuentan con UNIQLO y GU las cuales se enfocan 
principalmente en un mercado de consumo masivo más bajo, y, por otro lado, con J Brand o CDC que son marcas que ofrecen prendas más exclusivas y de mayores precios, dirigidas a un sector económico más alto.

\section{INNOVACIÓN SUPERIOR}

FR aplica dos tipos de innovación. En primer lugar, desarrolla innovación en sus productos a través de un equipo de Investigación \& Desarrollo que se encarga de mapear las tendencias del mercado, basándose en estas para la producción de prendas diferenciadas. En segundo lugar, se aplica también la innovación en los procesos. La empresa cuenta con el "Fast Retailing Management and Innovation Center" el cual se centra en preparar a futuros líderes para que dirijan la compañía y también en los Programas SAP, que se centran en la gestión de tienda, gestiones administrativas y gestión centrada en el producto. Al final de todo el programa, los participantes deben presentar una solución o un proyecto para resolver una problemática real que se viene dando en la compañía con el fin de llegar al billón de yenes de beneficios en el 2020. Es así como surgen los procesos innovadores dentro de la compañía.

\section{CALIDAD SUPERIOR}

El grupo FR se caracteriza actualmente por ofrecer productos a precios accesibles y de buena calidad. Por ejemplo, UNIQLO aplica la tecnología HEATTECH, las demás marcas premium del grupo como CDC, PTT y Theory utilizan materia prima como telas italianas, finos acabados en seda y algodón, entre otras.

Las ventajas competitivas de sus principales unidades de negocio son las siguientes:

\section{UNIQLO}

\section{EFICIENCIA SUPERIOR}

Para la producción de las prendas de UNIQLO, se realiza la adquisición de materia prima en diferentes partes del mundo, buscando que los precios de los proveedores sean más competitivos y generando economías de escala.

\section{CALIDAD SUPERIOR}

Inicialmente, UNIQLO estaba caracterizado por ser una marca que ofrecía prendas de baja calidad a bajo precio. Es en el 2004 donde inicia el proceso de cambio de la imagen 
de su marca y busca centrarse en la calidad como una característica diferenciadora, es decir, ahora ofrecerían precios competitivos y ropa de buena calidad.

Debido a ello, empezaron a producir prendas con materia prima de mayor calidad e implementaron HEATTECH, la cual representa una calidad superior. Además, la empresa cuenta con un equipo de especialistas técnicos que realizan visitas a las fábricas donde se produce la ropa con el fin de inspeccionar la calidad de los productos y sugerir mejoras en los procesos.

\section{SUPERIOR SATISFACCIÓN DE ATENCIÓN AL CLIENTE}

UNIQLO desarrolla sus productos en base a los requerimientos de sus clientes. La marca cuenta con un centro de atención al cliente el cual recibe más de 70000 opiniones y solicitudes anuales que les permiten a los departamentos involucrados en el desarrollo de producto y contacto final con el cliente, mejorar los detalles relacionados a los materiales de las prendas, las tiendas y los servicios como la atención al cliente. Un ejemplo de cómo la opinión del cliente impacta en el negocio es el desarrollo de HEATTECH, ya que éstos demandaban utilizar telas más suaves para evitar resequedad en la piel o mayor variedad de colores en sus prendas.

En el año 2017, la compañía recibió un total de 4969785 comentarios y/o sugerencias a través del correo electrónico o la App de UNIQLO, después de realizada una compra. El siguiente gráfico muestra los resultados de la encuesta de satisfacción al cliente:

\section{Figura 1.4}

Resultados de la encuesta de satisfacción al cliente (UNIQLO)

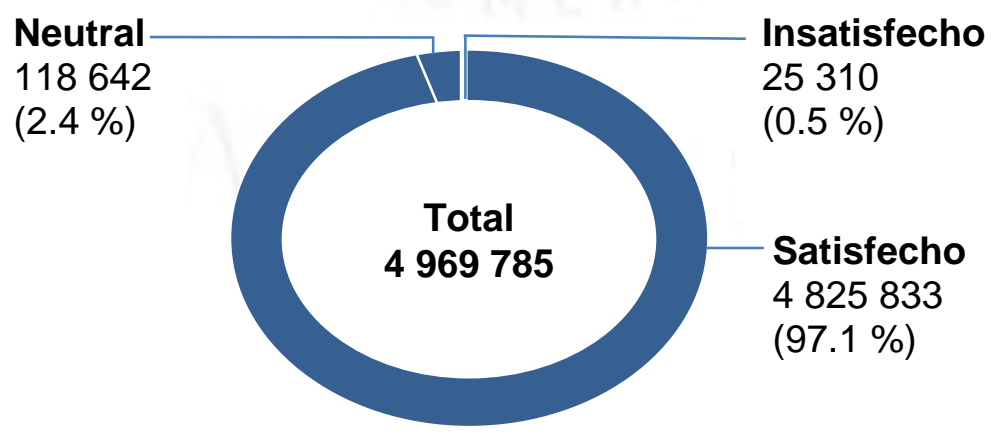

Fuente: Fast Retailing. (2018).

Elaboración propia 


\section{GU}

\section{EFICIENCIA SUPERIOR}

Lo que busca GU es ofrecerle al cliente final un producto que coincida con las tendencias de la moda actual y que pueda ser adquirido a un bajo precio, para lo cual buscan flexibilizar su cadena de producción y adquirir materia prima a precios bajos aplicando el modelo SPA.

\section{MARCAS GLOBALES}

\section{CALIDAD SUPERIOR}

La principal ventaja competitiva de las marcas globales que maneja Fast Retailing es la calidad superior.

Theory se enfoca en ofrecerle a los clientes prendas de calidad superior mediante telas italianas de alta calidad y un estilo sofisticado.

CDC es la marca del grupo que está enfocada en la moda femenina, elegante e informal. Es conocida por ofrecerle a sus clientes prendas de alta calidad y de diseños exclusivos con precios accesibles, que representan el espíritu de la mujer francesa.

Por último, PTT ofrece lencería, ropa para estar en casa y trajes de baño exclusivamente para mujeres. Las prendas de esta marca se caracterizan por fabricarse con los más finos acabados en seda y algodón, incluidos detalles hechos a mano.

\subsubsection{Determinación y sustentación de las Fortalezas y Debilidades de la empresa y por UEN (Unidad Estratégica de Negocios)}

\section{Fast Retailing}

\section{Fortalezas}

$\underline{\text { Presencia a nivel mundial }}$

Actualmente, Fast Retailing se ha expandido geográficamente a casi todos los continentes. Cuenta con 2068 tiendas de UNIQLO, 393 de GU, y 984 entre Theory, CDC y PTT, lo cual suma un total de 3445 tiendas localizadas en diferentes partes del mundo. Gracias a esta expansión, el grupo ha obtenido ciertas ventajas como: 
- Mitigar los riesgos asociados a manejar sus operaciones en un solo mercado.

- Obtener mayores ingresos y generar mayores utilidades.

\section{$\underline{\text { Variedad de marcas dirigidas a diferentes mercados }}$}

Fast Retailing maneja 7 marcas diferentes para los mercados en los cuales tiene presencia: UNIQLO, GU, Theory, PLST, Comptoir Des Cotonniers, Princesse Tam Tam y J Brand. La variedad de marcas dirigidas a los distintos segmentos de mercado le permite a FR tener una mayor participación de mercado.

\section{Modelo de negocio SPA}

El modelo SPA se basa en el control total de la cadena de suministro de FR. Esto le permite manejar todo el proceso de negocio, desde la planificación y el diseño hasta la adquisición de material, producción, control y de calidad, ajustes de inventario y operaciones de tienda.

\section{Grandes volúmenes de producción}

Los grandes volúmenes de producción le permiten a la empresa manejar economías de escala, ya que para abastecer a todas las marcas que gestiona debe adquirir gran cantidad de materia prima.

\section{Formación y capacitación del personal de la empresa}

El "Fast Retailing Management and Innovation Center" fue lanzado en el año 2009 con el fin de capacitar a futuros líderes y promover la innovación en la organización. Este programa consistía en lo siguiente:

- Programa M: Se basaba en la incorporación de los 23 principios de gestión.

- Programa SAP: Capacitación en la Gestión de Tienda, Gestión Administrativa y Gestión Centrada en el Producto.

- Desafío individual: El proyecto final buscaba descubrir alguna problemática de la empresa, incorporar medidas correctivas y, por último, demostrar que los resultados tendrían un impacto positivo en los próximos 3 años.

\section{Debilidades}

$\underline{\text { Alto nivel de inversión en publicidad }}$ 
Fast Retailing debe invertir grandes cantidades de dinero en publicidad con el fin de potenciar la imagen de sus marcas y hacerlas más competitivas frente a otras de origen americano o europeo como Zara, Gap o H\&M que tienen un posicionamiento más fuerte.

\section{Presencia nula en América Latina}

Las operaciones de Fast Retailing principalmente están centradas en Asia, Europa y Estados Unidos. A la fecha, la empresa aún no ha abierto ninguna tienda en América del Sur o México lo cual representa una desventaja frente a sus competidores directos como H\&M, Zara y Gap, quienes ya tienen varios años en estos mercados.

\section{$\underline{\text { Falta de planeamiento en nuevas inversiones }}$}

Durante el proceso de expansión de las marcas que maneja Fast Retailing han experimentado ciertos problemas a la hora de adaptar sus conceptos a los diferentes mercados. Por ejemplo, 3 años después de que UNIQLO estableció su departamento de diseño en Nueva York, éste tuvo que cerrar, juntamente con el de 3 nuevos negocios textiles. Lo mismo le sucedió con la apertura de tiendas en Londres, abrieron 20 tiendas y cerraron 16 en un lapso menor a 2 años.

Adicionalmente, al momento de querer hacer una diversificación no relacionada entrando al negocio de la agricultura bajo el concepto SPA, FR se enfrentó a grandes pérdidas y el cierre del negocio en menos de 2 años.

\section{UNIQLO}

\section{Fortalezas}

$\underline{\text { Productos desarrollados en base a los requerimientos de los clientes }}$

UNIQLO cuenta con un centro de atención al cliente el cual recibe todos los comentarios y sugerencias de mejora de los consumidores con respecto a los productos, la tienda y los servicios ofrecidos. Toda esta información es trasladada a las áreas involucradas, permitiendo establecer un proceso de mejora continua.

\section{Experiencia en tienda}

Uno de los pilares para la diferenciación de UNIQLO es la calidad del servicio de la tienda lo cual implica tener un personal capacitado y atento, mantenerla limpia, tener un buen surtido de productos, mantener stock de los productos que se encuentran en oferta, entre otros factores. 
$\underline{\text { Relaciones exclusivas con sus proveedores }}$

UNIQLO mantiene relaciones estrechas con sus proveedores. Aproximadamente, el $80 \%$ de los productos son fabricados en China, permitiéndole abaratar sus costos en mano de obra.

\section{Marca posicionada en Asia, Europa y América del Norte}

La marca ya está totalmente posicionada en el continente asiático, en especial en Japón, donde es la fast fashion líder en ventas. Su expansión acelerada le ha permitido también posicionarse en Europa y en América del Norte (a excepción de México) como uno de los principales líderes en el negocio textil.

\section{$\underline{\text { Innovación de productos }}$}

Para que UNIQLO pase a ser una marca de bajo precio y baja calidad a una de bajo precio y alta calidad, desarrolló HEATTECH lo cual permite que sus prendas sean finas, suaves y cálidas. Asimismo, también implementó una tecnología textil llamada Airism que permite absorber el sudor de la piel y expulsarlo.

\section{$\underline{\text { Asistencia técnica de expertos en las fábricas }}$}

UNIQLO cuenta con un grupo de especialistas técnicos encargados de visitar las fábricas donde se producen las prendas con el fin de supervisar los procesos productivos y verificar el mantenimiento del control de calidad.

\section{$\underline{\text { Responsabilidad social corporativa }}$}

Otro de los pilares de diferenciación de UNIQLO es trabajar su posicionamiento en base al valor social para lo cual ha desarrollado diferentes tipos de actividades. En primer lugar, maneja iniciativas de reciclaje de todos sus productos. En segundo lugar, incentivó la contratación de personas con discapacidad superando lo mínimo establecido por ley en Japón, y, en tercer lugar, desarrolló un proyecto que consistía en emprender un negocio social en Bangladesh.

\section{Debilidades}

\section{Problemas para entrar a nuevos mercados}

Por más de que UNIQLO sea la fast fashion líder en Japón y tenga presencia a nivel internacional, aún le cuesta posicionarse como marca en los diferentes mercados globales 
a los que se va expandiendo. Esto se ha visto reflejado en los intentos fallidos de expansión como el de Nueva York y el de Londres.

\section{Bajo costo de cambio por parte del cliente}

El costo de cambio del cliente es bajo. Si no le gusta la oferta de UNIQLO o la experiencia de compra en la tienda, fácilmente puede optar por buscar otros productos de los competidores. Es por esto que la empresa tiene esforzarse en fidelizar a sus clientes y buscar, de alguna manera, diferenciar sus productos.

\section{$\underline{\text { Lenta expansión internacional }}$}

Los principales competidores de la industria han globalizado sus operaciones en prácticamente todos los continentes, ubicándose en los principales países y ciudades a nivel mundial. La expansión internacional de UNIQLO es más lenta, aún le falta expandirse a muchos países, dándole ventaja a los competidores.

\section{GU}

\section{Fortalezas}

\section{Tiempo en el mercado asiático}

La marca ya tiene 12 años en el mercado desde su creación en el año 2006. Actualmente tiene aproximadamente 358 tiendas en Japón y recientemente ha iniciado su expansión en el continente asiático comenzando en China y Taiwán.

\section{Modelo SPA}

Al igual que UNIQLO, GU también aplica el modelo SPA, es decir, tiene el control total de sus procesos productivos, lo cual le permite mantener costos bajos y ofrecer precios bajos.

$\underline{\text { Productos basados en las últimas tendencias de la moda }}$

Los productos desarrollados por GU se centran en ofrecer las últimas tendencias de la moda a precios accesibles.

\section{Debilidades}

\section{$\underline{\text { Mayor enfoque a UNIQLO }}$}


Debido a que UNIQLO es la marca bandera del grupo FR, probablemente GU reciba una menor atención o los recursos asignados no sean los mismos.

$\underline{\text { Posicionamiento en un solo mercado }}$

A diferencia de las otras UEN que maneja el grupo FR, las cuales se encuentran posicionadas a nivel global, GU únicamente se enfoca en el mercado asiático.

\section{Marcas Globales}

\section{Fortalezas}

\section{$\underline{\text { Productos de alta calidad }}$}

Las marcas globales que maneja FR se centran en ofrecer productos de alta calidad, caracterizados por utilizar materia prima de altos estándares.

\section{Diversificación}

Las diferentes marcas dentro de esta UEN están enfocadas a diferentes segmentos y regiones. Algunas están establecidas en el mercado norteamericano y ofrecen ropa urbana, mientras que otras están establecidas en Europa y comercializan ropa interior.

\section{Debilidades}

\section{Competencia con marcas premium posicionadas}

Las empresas que compiten con las marcas globales de FR ya se encuentran posicionadas en el mercado de ropa premium, por lo que se dificulta captar a nuevos clientes.

\subsection{DIAGNÓSTICO EXTERNO}

\subsubsection{Análisis PEST}

\section{Político}

- Incertidumbre política debido a los casos de corrupción que está viviendo actualmente el estado peruano.

\section{Económico}

- $\quad$ El Perú está ubicado dentro de los 10 mejores países para invertir dentro del sector retail. 
- El Perú está experimentando un crecimiento económico sostenido durante dos décadas.

- Desde hace 4 años, las ventas en provincia han experimentado un crecimiento constante en el sector retail, se espera que en el 2020 lleguen a representar el $50 \%$.

- En el 2017, la inversión en apertura de nuevos centros comerciales ascendió a S/ 664 millones. Se espera que en el lapso del 2018 y 2019, la inversión ascienda a S/ 1800 millones.

\section{$\underline{\text { Económico - Ambiental }}$}

- Las ventas de las tiendas departamentales han ido disminuyendo por factores macroeconómicos, como la debilidad del consumo y el fenómeno del Niño Costero, y también por el ingreso de las fast fashion.

\section{$\underline{\text { Político - Económico }}$}

- Iniciativas por parte del gobierno para promover la integración comercial y buscar tratados de libre comercio con diferentes países, esto ha impulsado la inversión en el sector textil.

- La compra de indumentaria ha disminuido entre $10 \%$ y $15 \%$ debido a la falta de inversión por problemas políticos y económicos.

\section{$\underline{\text { Tecnología }}$}

- Implementación de nuevas tecnologías en la experiencia de compra del cliente en tienda.

- Incursión de operadores mundiales de E-Commerce en Perú.

- Fortalecimiento del canal de venta online en el Perú.

\section{$\underline{\text { Social }}$}

- Aumento del índice de desempleo como resultado de los casos de corrupción en el sector construcción.

- Empoderamiento de los consumidores debido a la globalización y al acceso de información.

- El sector retail aporta positivamente a la empleabilidad, especialmente promoviendo el trabajo juvenil. 


\subsubsection{Análisis de las fuerzas competitivas del sector industrial}

Para analizar las fuerzas competitivas del sector retail, se desarrollarán "Las 5 Fuerzas de Porter".

\section{$\underline{\text { Poder de negociación de los compradores: Bajo }}$}

Los compradores de UNIQLO son los clientes individuales que van a las tiendas de la marca, es decir, los usuarios finales de las prendas. La ropa ofrecida por la marca tiene precios establecidos que no pueden ser negociados a la hora de ejercer la compra.

De igual manera, el comprador es sensible al precio, por lo que UNIQLO tiene la presión para mantener sus costos bajos. En caso lo dejase de hacer, y debido a la alta competencia que hay en el sector, es fácil que el usuario final decida migrar a la competencia.

\section{Poder de negociación de los proveedores: Bajo}

Por más de que UNIQLO mantenga relaciones estrechas con aproximadamente 80 proveedores, la cantidad de oferta que hay en esta industria es mucha a comparación de la cantidad de compradores. Esto significa que los proveedores tienen un bajo margen de negociación de precios.

UNIQLO busca estandarizar sus productos para ahorrar en los procesos productivos, por lo tanto, varios proveedores podrían realizar esta labor.

Asimismo, la adquisición de materia prima que realiza la empresa para su producción es en grandes volúmenes, convirtiendo a UNIQLO en un comprador clave y un generador de ingresos, vital para sus proveedores. Esto se refleja en una presión por mantener los costos bajos.

Los proveedores que se dedican a la confección de prendas o al abastecimiento de la materia prima que requiere UNIQLO, no representan una amenaza de integración hacia adelante mientras que UNIQLO sí representa una amenaza con una posible integración hacia atrás.

\section{Amenaza de ingreso de competidores potenciales: Baja}


Inicialmente, para que la empresa pueda posicionarse como un competidor potencial debe invertir grandes sumas de dinero en temas como infraestructura (habilitación de tiendas), capital humano (administrativo y operativo), marketing, distribución, entre otros elementos involucrados al negocio.

También es un factor determinante en la industria desarrollar economías de escala debido al gran nivel de producción que se maneja en este negocio y para desarrollar una ventaja competitiva en base a bajos costos. La gran cantidad de compras de materia prima genera una disminución en los costos, ya que a mayor volumen de compra los costos disminuyen.

Adicional a esto, las marcas que están involucradas en esta industria tienen una presión por diferenciarse ya sea por calidad, moda o precio, siendo las principales formas de crear una relación con el consumidor y fidelizarlo. Normalmente, los usuarios prefieren optar por marcas que ya están posicionadas en el mercado en vez de arriesgarse por una nueva.

Por último, las marcas que actualmente se encuentran en el mercado, han invertido gran cantidad de recursos en fidelizar a sus clientes, creando un vínculo marca-cliente que con dificultad puede ser quebrado. La lealtad de marca es un factor muy importante en la competencia de hoy en día.

Amenaza de productos sustitutos: Baja

Se podría considerar que la ropa casual tiene muchos sustitutos como la ropa deportiva, la ropa formal, la ropa para estar en casa, entre otras; sin embargo, cada tipo de ropa se presta para situaciones diferentes. UNIQLO se diferencia de la gran variedad de marcas que comercializan ropa casual por los bajos precios que manejan.

Estos últimos factores mencionados, hacen que UNIQLO ofrezca ropa casual difícil de imitar o de substituir.

\section{$\underline{\text { Rivalidad entre los competidores: Alta }}$}

La estructura de competidores de la industria de las fast fashion es consolidada, hay pocos competidores, pero la mayoría de estos son grandes marcas que están posicionadas en casi todos los mercados. 
Como este concepto de negocio es relativamente nuevo para el mercado peruano, aún tiene muchas oportunidades de crecimiento. Un desarrollo sostenido del sector implica que la demanda seguirá aumentando. Los competidores desarrollarán estrategias para abarcar el mayor porcentaje de participación de mercado.

Las barreras de salida de la industria son altas debido a la gran inversión en infraestructura y activos que la empresa debe hacer para ser competitiva, adicionalmente a la gran cantidad de personal que debe contratar para supervisar y ejecutar su operación.

Además, al ser una empresa familiar, existe un apego emocional que dificultaría el cierre del negocio en caso sea necesario.

\subsubsection{Determinación y sustentación de las Oportunidades y Amenazas}

\section{Oportunidades}

\section{$\underline{\text { E-Commerce como canal para la venta }}$}

Actualmente, en el mercado nacional las tiendas departamentales son las que están dominando el E-Commerce principalmente con la venta de electrodomésticos y productos tecnológicos, mientras que la moda aún está en segundo plano.

\section{Consumidor globalizado}

Con la llegada de la globalización, el peruano es un cliente más informado: conoce de tendencias de la moda, ofertas a nivel mundial, marcas, estilos de vida, entre otros temas. Por ejemplo, la expectativa de llegada de las fast fashion al Perú fue bastante grande debido a que los consumidores ya sabían de la existencia de estas marcas y los productos que ofrecían.

\section{$\underline{\text { Desarrollo del retail en provincias }}$}

En los últimos 4 años, las ventas del sector retail en provincia han experimentado un crecimiento sostenido. Se espera que para el 2020 lleguen a representar el $50 \%$.

$\underline{\text { Tendencia de modelo de negocio en el descuento o precios bajos }}$

Este modelo de negocio es el que predomina en UNIQLO, ofrecer productos de buena calidad, pero a precios bajos.

\section{Desaceleración de ventas departamentales}


Las ventas de las tiendas departamentales se han venido desacelerando desde hace algunos años, principalmente por factores macroeconómicos como la debilidad del consumo y por problemas con el fenómeno climático del Niño Costero.

\section{Amenazas}

\section{$\underline{\text { Imitación de productos }}$}

La imitación de productos es uno de los factores más preocupante para las marcas que tienen una imagen global posicionada. Esto se da especialmente en economías emergentes y países de bajos ingresos, ya que normalmente las imitaciones se dan en productos que no tienen alcance en estos mercados; es decir, que aún no han ingresado. Esto produce un impacto negativo en la imagen y calidad de la marca y sus productos.

\section{$\underline{\text { Presencia de competidores en el mercado nacional }}$}

Las principales empresas del mercado de las fast fashion llegaron a Perú a partir del 2012 con el ingreso de Zara, la marca insignia de Inditex. En el 2014, llegó Forever 21 y en el 2015, H\&M. Esto les ha dado una ventaja significativa con respecto a los tiempos de adaptación al mercado, conocimiento del consumidor, posicionamiento, entre otros factores.

\section{$\underline{\text { Inestabilidad política }}$}

El Perú está viviendo una crisis política y un aumento en la corrupción que afecta la imagen del país de manera crítica. El escenario es incierto, inestable y preocupante lo cual puede impactar negativamente en las inversiones.

\section{Competencia innovadora}

Las nuevas tecnologías desarrolladas por los competidores son una amenaza para la industria. Por ejemplo, actualmente Zara se encuentra trabajando en la innovación del proceso de compra con la implementación de una nueva tienda que combinará los elementos físicos con los virtuales. Este competidor será considerado un disruptor de las tecnologías de la industria.

\section{$\underline{\text { Negocios de ropa detenidos }}$}

Como resultado de los problemas políticos - económicos que estamos atravesando, la inversión en compra de indumentaria ha disminuido entre $10 \%$ y $15 \%$. 


\section{CAPÍTULO II: FORMULACIÓN DE LA ESTRATEGIA}

\subsection{Desarrollo y sustentación de la matriz EFI}

Tabla 2.1

Matriz EFI

\section{\begin{tabular}{l|l|c} 
VALOR & CLASIFICACIÓN & V. \\
PONDERADO
\end{tabular}}

\section{FORTALEZAS}

1.- Productos desarrollados en base a los requerimientos del cliente

2.- Experiencia en tienda

3.- Relaciones exclusivas con sus proveedores

4.- Marca posicionada en Asia, Europa y Estados Unidos

5.- Innovación de productos

6.- Asistencia técnica de expertos en las fábricas

7.- Responsabilidad social corporativa

\begin{tabular}{l|l|l}
0.06 & 3 & 0.18
\end{tabular}

DEBILIDADES

8.- Problemas para entrar a nuevos mercados

9.- Bajo costos de cambio

10.- Lenta expansión internacional

Fuente: Louffat, E. (2015).

Elaboración propia

UNIQLO tiene un valor ponderado por encima de 2.50 lo que significa que las fortalezas internas de la empresa predominan sobre sus debilidades.

De igual manera, las debilidades de la empresa son preocupantes, se deben plantear estrategias para tener un mejor posicionamiento y penetración en los mercados que se ya tiene presencia y a los que se entrará próximamente. También, aumentar la diferenciación de sus productos para obtener una ventaja sobre la competencia e incrementar el costo de cambio del cliente. Por último, los principales competidores del rubro se expanden velozmente en países que UNIQLO aún no tiene presencia, 
estableciéndose y conociendo a los consumidores de estos mercados, lo cual les da una ventaja.

\subsection{Desarrollo y sustentación de la Matriz EFE}

Tabla 2.2

Matriz EFE

\section{\begin{tabular}{l|c|c} 
VALOR & CLASIFICACIÓN & V. \\
& PONDERADO
\end{tabular}}

OPORTUNIDADES

1.- E-Commerce como canal para la venta

2.- Consumidor globalizado

3.- Desarrollo del Retail en provincia

4.- Tendencia en el modelo de negocio en el descuento o precios bajos

5.- Desaceleración de las ventas departamentales

\section{0.}

\begin{tabular}{l|l}
0 & 0.14 \\
\hline
\end{tabular}

14

(19

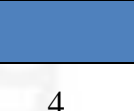

(1)

\section{AMENAZAS}

\begin{tabular}{|l|c|c|c|}
\hline 8.- Imitación de productos & 0.07 & 2 & 0.14 \\
\hline $\begin{array}{l}\text { 9.- Presencia de } \\
\text { competidores en el mercado } \\
\text { nacional }\end{array}$ & 0.10 & 3 & 0.30 \\
\hline $\begin{array}{l}\text { 10.- Inestabilidad política } \\
\begin{array}{l}\text { 11.- Competencia } \\
\text { innovadora }\end{array}\end{array}$ & 0.06 & 2 & 0.12 \\
\hline $\begin{array}{l}\text { 12.- Negocios de ropa } \\
\text { detenidos }\end{array}$ & 0.09 & 3 & 0.16 \\
\hline
\end{tabular}

Fuente: Louffat, E. (2015).

Elaboración propia

El resultado del valor ponderado de la matriz EFE es de 2.70 lo que significa que UNIQLO sabe aprovechar las oportunidades y responder ante las amenazas.

Con respecto a las oportunidades, se considera que UNIQLO cuenta con las cualidades necesarias para aprovecharlas. En el Perú, la preferencia de compra por el canal de venta online se encuentra en aumento, hay crecimiento en la demanda de los 
productos comercializados por este medio. Adicionalmente, la globalización ha permitido que los consumidores obtengan más información antes de obtener un producto, por ende, tendrán conocimiento de la calidad y los precios que maneja la marca antes de que llegue al país. Por otro lado, el desarrollo del retail en provincia le permitirá ingresar a un mercado que aún no ha sido explotado y la tendencia del modelo de negocios en el descuento o precios bajos facilitará este ingreso ya que es la característica diferenciadora que diferencia a UNIQLO. Por último, la desaceleración de las ventas departamentales es una oportunidad para que la participación de mercado de las fast fashion siga aumentando.

Por el lado de las amenazas, la imitación de productos siempre estará presente al ser una marca globalizada y de calidad. Asimismo, los principales competidores ya tienen presencia en el mercado nacional representando una amenaza ya que, con el tiempo, han ido desarrollando estrategias para adaptarse a las necesidades de los consumidores peruanos. También observamos un país con problemas de corrupción que a corto mediano plazo podría impactar en las inversiones extranjeras, sumado a la disminución de la inversión en compra de indumentaria, representa un problema económico. Por último, la competencia ya inicio con innovaciones disruptivas que impactarán en las tecnologías del rubro.

\subsection{Matriz de las Estrategias Genéricas}

Figura 2.1

Matriz de las Estrategias Genéricas

\begin{tabular}{|c|c|c|c|}
\hline \multicolumn{3}{|c|}{ ESTRATEGIAS GENERICAS } \\
\hline \multicolumn{2}{|c|}{ MERCADO MASIVO } & \multicolumn{2}{c|}{ MERCADO REDUCIDO } \\
\hline LIDER EN COSTOS & DIFERENCIACIÓN & DNFOQUE \\
\hline \multirow{2}{*}{$\begin{array}{l}\text { SEGMENTO } \\
\text { PROMEDIO }\end{array}$} & SEGMENTOS DIFERENTES & $\begin{array}{c}\text { LIDER EN } \\
\text { COSTOS }\end{array}$ & NICHO \\
\cline { 3 - 4 } & & NICHO & \\
\hline \multicolumn{2}{|c|}{$\begin{array}{l}\text { DIDER EN COSTOS + DIFERENCIACION } \\
\text { DIFERENCIACIÓN AMPLIADA }\end{array}$} & & \\
\hline
\end{tabular}

Fuente: Louffat, E. (2015).

Elaboración propia 
Dentro de la Matriz de las Estrategias Genéricas, UNIQLO clasifica como un Líder en Costos con Diferenciación que se denomina Diferenciación Ampliada.

En primer lugar, los productos de UNIQLO van dirigidos hacia un mercado masivo, su oferta es amplia y abarca a mujeres y hombres en un rango de edad entre 20 y 60 años, y también a niños.

Dentro del mercado masivo en el que se desenvuelve la empresa y por la competencia, es necesario buscar el liderazgo en costos o la diferenciación. En el caso de UNIQLO, posee ambas cualidades, logra ser un líder en costos debido a su aprovisionamiento global en volúmenes grandes para lograr economías de escala, emplea el modelo SPA lo cual le da el control de todos sus procesos de la cadena de suministro desde el planeamiento hasta las operaciones en tienda, producción en China con el fin de disminuir los costos en mano de obra. Estos factores le permiten a la marca mantener sus costos bajos y, por ende, brindar los mejores precios a los clientes.

Por el lado de la diferenciación, UNIQLO no solo se guía por los precios a la hora de adquirir materia prima, sino también en la calidad de los suministros. Adicionalmente, le da mayor calidad a sus productos con las tecnologías HEATTECH y Airism, también cuenta con un equipo de asistencia técnica desplegado en las fábricas donde se producen los productos con el fin de brindar apoyo en el mantenimiento del control de la calidad y mejora continua, y por último, trabajan colaboraciones de diseños con artistas reconocidos a nivel mundial.

\subsection{Matriz FODA}

En la matriz FODA se desarrollarán los principales factores internos (fortalezas y debilidades) y los externos (oportunidades y amenazas), con el fin de desarrollar estrategias relacionadas a los objetivos del negocio. 
Figura 2.2

\section{Matriz FODA}

\begin{tabular}{|c|c|}
\hline OPORTUNIDADES & AMENAZAS \\
\hline $\begin{array}{l}\text { O.1 E-Commerce como canal para la } \\
\text { venta }\end{array}$ & A.1 Imitación de productos \\
\hline O.2 Consumidor globalizado & $\begin{array}{l}\text { A.2 Presencia de competidores } \\
\text { en el mercado nacional }\end{array}$ \\
\hline O.3 Desarrollo del retail en provincia & A.3 Inestabilidad política \\
\hline $\begin{array}{l}\text { O.4 Tendencia en el modelo de } \\
\text { negocio en el descuento o precios } \\
\text { bajos }\end{array}$ & A.4 Competencia innovadora \\
\hline $\begin{array}{l}\text { O.5 Desaceleración de las ventas } \\
\text { departamentales }\end{array}$ & $\begin{array}{l}\text { A.5 Negocios de ropa detenidos } \\
\text { por la coyuntura político- } \\
\text { económica }\end{array}$ \\
\hline ESTRATEGIA FO & ESTRATEGIA FA \\
\hline $\begin{array}{l}\text { F.1 - O.2: Desarrollar productos que } \\
\text { cumplan con las expectativas del } \\
\text { consumidor peruano. Bajo precio, alta } \\
\text { calidad. } \\
\text { F.3 - O.4: Seguir desarrollando } \\
\text { economías de escala con el fin de } \\
\text { reducir costos y ofrecer precios bajos. } \\
\text { F.7 - O.2: Implementar un modelo de } \\
\text { negocio relacionado con el apoyo a las } \\
\text { comunidades más pobres como el } \\
\text { reciclaje de ropa. } \\
\text { F.5 - O.1: Ingresar al mercado online } \\
\text { con los productos más innovadores y } \\
\text { característicos de la marca. }\end{array}$ & $\begin{array}{l}\text { F.3 - A.1: Mantener los costos } \\
\text { bajos de desarrollo de producto } \\
\text { para ofrecer los mejores precios } \\
\text { y no darle margen de } \\
\text { oportunidad a la imitación de } \\
\text { productos. } \\
\text { F.2 - A.4: Aplicar una estrategia } \\
\text { innovadora defensiva y ser un } \\
\text { seguidor tecnológico, } \\
\text { momentáneamente, de Inditex. } \\
\text { F.5 - A.2: Ingresar al mercado } \\
\text { con los productos más } \\
\text { innovadores para obtener una } \\
\text { diferenciación sobre los } \\
\text { productos de la competencia }\end{array}$ \\
\hline ESTRATEGIA DO & ESTRATEGIA DA \\
\hline $\begin{array}{l}\text { D.1 - O.4: Desarrollar estrategias } \\
\text { enfocadas en los precios bajos } \\
\text { aprovechando que la tendencia del } \\
\text { mercado se acomoda al modelo de } \\
\text { negocio de UNIQLO, con el fin de } \\
\text { lograr una expansión exitosa. } \\
\text { D.2 - O.2: Campañas agresivas de } \\
\text { marketing relacionadas al precio y la } \\
\text { calidad con el fin de que los } \\
\text { consumidores peruanos se comiencen } \\
\text { a relacionar con la marca. }\end{array}$ & $\begin{array}{l}\text { D.3 - A.2: Expansión agresiva } \\
\text { en el mercado nacional. Ingresar } \\
\text { a la capital y realizar una } \\
\text { penetración de mercado rápida a } \\
\text { provincia. } \\
\text { D.1 - A.1: Ingresar al mercado } \\
\text { enfocándose en los precios bajos } \\
\text { para evitar en lo posible la } \\
\text { imitación de sus productos. }\end{array}$ \\
\hline
\end{tabular}

Fuente: Louffat, E. (2015).

Elaboración propia 


\subsection{Definición y sustentación de la Visión, Misión y Políticas}

Misión

- Crear ropa excelente con un valor nuevo y exclusivo, y permitir a las personas de todo el mundo experimentar la alegría, la felicidad y la satisfacción de poder ponérsela.

- Enriquecer la vida de las personas mediante nuestras actividades corporativas exclusivas, y hacer crecer y desarrollar nuestra compañía en línea con la sociedad.

La misión va amarrada al propósito de la organización y está bien definido en su declaración. Fast Retailing quiere ofrecerles a sus clientes ropa excelente sin importar los diferentes estilos de vida, quieren unificar a las personas mediante tendencias o ideas trascendiendo fronteras, culturas, religiones, entre otros factores. Buscan que las personas se sientan bien, cómodas, únicas a la hora de usar sus productos.

FR también busca promover la responsabilidad social empresarial mediante actividades como su proyecto social en Bangladesh o creando conciencia con respecto al medio ambiente guiándose por sus políticas de sostenibilidad. Buscan contribuir con la sociedad y colaborar con el desarrollo de un mundo mejor.

$\underline{\text { Visión }}$

Ser la compañía líder en el sector textil mundial para el 2020.

Para el 2020, Fast Retailing se quiere posicionar como la empresa número 1 en la industria superando a Inditex y H\&M los cuales actualmente se encuentran por encima.

Para cumplir con esta visión FR aún debe seguir expandiéndose a nivel mundial y continuar con su crecimiento como empresa. En esta visión empresarial deben estar involucrados todo el personal de la empresa, todos deben apuntar hacia la misma dirección con el fin de posicionarse como el líder del rubro. Los 23 principios de gestión implementados por Yanai son la guía para para seguir creciendo y mejorar las deficiencias que se vayan presentando en el día a día, es importante que todos los trabajadores sepan cómo interpretarlos y aplicarlos es por esto que dentro del FRMIC se desarrolla el "Programa M" y al final los participantes deben proponer proyectos que le 
permitan a la empresa alcanzar 1 billón de yenes de beneficios de las ventas de 5 billones de yenes.

\section{$\underline{\text { Políticas }}$}

Las políticas de Fast Retailing se basan en la sostenibilidad del negocio. Detallaremos algunas de las principales políticas que maneja la compañía.

\section{$\underline{\text { Política de Cadena de Suministro }}$}

FR monitorea las actividades de la Cadena de Suministro que impactan en el medio ambiente con el fin de buscar mejoras o problemas y tomar medidas correctivas con respecto a diversas situaciones. La empresa también es responsable a la hora de gestionar las compras y es transparente con sus proveedores, buscando una colaboración mutua con el fin de lograr impactos positivos en la industria y desarrollar un proceso de mejora continua.

Adicionalmente, la empresa busca reducir las emisiones de $\mathrm{CO} 2$, gestionar los químicos, el agua y los desperdicios relacionados a la producción. También, respetar y promover los derechos humanos de los trabajadores por lo cual no se permite ninguna clase de abuso y se les brinda unas condiciones laborales decentes.

\section{Política de Productos Responsables}

FR evalúa todo el proceso productivo de sus productos, desde el diseño hasta el uso por el cliente, preocupándose por el medio ambiente y la sostenibilidad. Para esto aplica ciertas políticas como buscar o utilizar materia prima y algodón más sostenible, incrementar el uso de materiales reciclados en la producción con el fin de no utilizar nueva materia prima, no suministros basados en madera con el fin de detener la tala de árboles y no afectar a las comunidades que dependen de los boques, y por último, no utilizar ningún material que esté involucrado con el maltrato animal.

\section{$\underline{\text { Política de Tienda y Comunidad }}$}

FR le brinda información y entrena al personal en cómo aportar al medioambiente mediante las actividades que realizan. También, a la hora de diseñar e implementar sus tiendas, buscan que los materiales a utilizarse sean eficientes y sostenibles sin impactar en la experiencia de compra del consumidor. Además, promueven la participación del personal en la innovación relacionada a la sostenibilidad. 
La empresa busca que sus tiendas tengan una gestión energética más eficiente, utilizar materiales sostenibles para la construcción de estas y mejorar la administración de sus desperdicios y el reciclaje de las mismas.

Con respecto a la comunidad, FR promueve ciertas actividades para que las comunidades se involucren con el desarrollo del negocio como donar ropa, ofrecer trabajo y oportunidades de educación y analizar el problema de algunos grupos vulnerables que se vean afectados por la problemática mundial. También, brindar apoyo en los lugares donde las personas se ven afectadas por desastres naturales.

\section{$\underline{\text { Política de Trabajadores }}$}

Para FR es importante mantener la sinergia entre la empresa y sus empleados alrededor del mundo, hacerlos sentir que son parte vital del negocio y que se sientan orgullosos de las labores que hacen y de los beneficios que aportan. El crecimiento de los trabajadores es el crecimiento de la empresa.

FR promueve la igualdad, diversidad e inclusión de las personas, por lo tanto, no se fijan en tu religión, etnia, raza, etc. La discriminación está prohibida en la empresa. Asimismo, capacitan y desarrollan las habilidades de las personas mediante el FRMIC y promueven la mentalidad Global One que se centra en tomar decisiones con la mentalidad de un directivo. Por último, la empresa les brinda a sus trabajadores toda asistencia de salud que ellos requieran.

\subsection{Definición de los Objetivos Estratégicos de la Empresa}

\section{Expansión de UNIQLO al mercado de América del Sur para el 2019}

UNIQLO debe continuar con su expansión en mercados a los que aún no ha ingresado. A la marca aún le falta presencia en el mercado América del Sur.

Además, aún no se ha animado a incursionar en México el cual normalmente es la ventana de ingreso al grupo de países hispanohablantes ubicados en América del Sur. $\underline{\text { Incrementar las ventas del canal online en un } 2 \%}$

Hoy en día, la omincanalidad es un tema que todos los retailers deben contemplar si quieren ser exitosos. UNIQLO se ha sumado a esta tendencia de la venta online en países como Japón, Estados Unidos y China, pero el escenario se presta para seguir explotando 
este canal de venta. Muchos consumidores ahora prefieren adquirir productos online los cuales les llegarán a la puerta de sus casas o simplemente pasar por la tienda para recoger sus compras en vez de ir a una tienda física y realizar todo el proceso de compra.

$\underline{\text { Implementar innovaciones en la experiencia de compra del cliente }}$

Actualmente, Inditex es la empresa que está innovando en la experiencia de compra del cliente.

Fast Retailing debe comenzar a trabajar en implementar las tecnologías que se van presentando en la industria como los espejos-pantalla, RFID, entre otras. con el fin de que la experiencia de compra del cliente sea única y diferenciada. También, debe buscar innovación y optar por una estrategia ofensiva, es decir, ser un disruptor de las tecnologías asociadas al retail.

\section{$\underline{\text { Adaptación de la Cadena de Suministro }}$}

El Perú es uno de los países en los que se puede encontrar materia prima de calidad para la producción textil y en el que los costos de mano de obra son regulares. Fast Retailing debe evaluar si es factible adquirir algunos materiales en el mercado nacional o de implementar algún centro de producción con el fin de seguir minimizando costos. Hacer un comparativo entre los costos logísticos de producir en China y enviar la ropa desde allá o ver la forma de trasladar parte de su producción a fábricas localizadas en Perú.

\section{$\underline{\text { Incrementar el posicionamiento de marca a nivel global }}$}

El posicionamiento de marca de UNIQLO está centrando en el mercado japonés donde los clientes la identifican como la fast fashion líder del mercado, pero a nivel global, las marcas líderes de la industria se asocian a Zara, H\&M, GAP o Forever 21 más no con UNIQLO. Esto significa que aún le falta un posicionamiento de mercado a nivel global, sin embargo, la marca definitivamente ha estrado trabajado en esto, por ejemplo, hasta el 2017 Novak Djokovic era auspiciado por la marca por lo cual en cada partido que jugaba usaba la indumentaria de la marca, y en el presente año, han cerrado un contrato por 300 millones de dólares por 10 años con Roger Federer. Estas acciones colocan a la marca como una de las "top of mind" cuando la asocias a indumentaria relacionada al deporte. Este tipo de estrategias fortalecen el posicionamiento de la marca. 


\subsection{Redefinición de las UEN (Unidad Estratégica de Negocios) o creación de nuevas UEN}

Las Unidades Estratégicas de Negocio en el caso de Fast Retailing están clasificadas en 3: UNIQLO, GU y Marcas Globales.

Se han clasificado así debido a que estas tres unidades de negocio van dirigidas a diferentes sectores, las ventajas competitivas son diferentes e inclusive los competidores también varían.

UNIQLO va dirigido a un mercado masivo pero sus productos son diferenciados como resultados de la calidad de los suministros con los que son producidos, la ventaja competitiva de esta UEN se centra en la calidad, costos, innovación y capacidad de satisfacción del cliente, y su principal competencia son las fast fashion que se encuentran posicionadas a nivel global como Zara y H\&M. Por el lado de GU, va dirigido a un mercado masivo centrado en el continente asiático, ofrece precios bajos y su principal ventaja competitiva es la eficiencia superior. Por último, dentro de la UEN Marcas Globales están incluidas Theory, CDC y PTT las cuales ofrecen productos de mayor calidad, pero con precios más altos, la ventaja competitiva de estas marcas es la calidad superior.

\subsection{Propuesta y sustentación de Estrategias en el ambiente Global, Corporativas, de Negocios y Funcionales}

Fast Retailing ha aplicado diversas estrategias en las diferentes etapas en las que ha ido desarrollándose. Se detallarán algunas:

\section{Estrategias Corporativas}

Con el objetivo de ingresar a mercados nuevos e incrementar su oferta de productos, Fast Retailing ha ido adquiriendo diversas marcas enfocadas en mercados un sector premium. La estrategia que aplicó es una diversificación relacionada ya que las marcas adquiridas también comercializan productos textiles.

Como propuesta para el ingreso al mercado peruano, Fast Retailing podría aplicar alianzas estratégicas o joint ventures con algunas fábricas a nivel nacional que tengan conocimiento en el rubro de producción textil con el fin de tratar de reducir costos de 
fabricación y analizar la forma de aumentar la calidad. Adicionalmente, FR podría desplegar asistencia técnica para el mantenimiento de los controles de calidad y e incentivar la mejora continua.

\section{Estrategias de Negocios}

La estrategia de negocios que debe aplicar Fast Retailing es un Desarrollo de Nuevos Mercados. Se desarrollará la Matriz Ansoff con el fin sustentar la elección de la estrategia:

Figura 2.3

Matriz de Ansoff

\begin{tabular}{|c|c|c|c|}
\cline { 3 - 4 } \multicolumn{2}{c|}{} & \multicolumn{2}{c|}{ P R O D U C T O S } \\
\cline { 3 - 4 } \multicolumn{2}{c|}{} & ACTUALES & NUEVOS \\
\hline M & \multirow{2}{*}{ ACTUALES } & PENETRACIÓN & DESARROLLO DE \\
R & & NE MERCADO & PRODUCTOS \\
$\mathbf{C}$ & & & \\
A & & DESARROLLO & \\
D & \multirow{2}{*}{ NUEVOS } & DE NUEVOS & DIVERSIFICACIÓN \\
$\mathbf{O}$ & & MERCADOS & \\
S & & & \\
\hline
\end{tabular}

Fuente: Lerma Kirchner, A. E. (2017).

Elaboración propia

Como se observa, FR seguirá expandiendo sus operaciones a nuevos mercados, pero con la gama de productos actuales que maneja a nivel global, por ende, la estrategia de negocios que debe aplicar es un Desarrollo de Nuevos Mercados. Para esto, la empresa debe mapear bien los nuevos mercados geográficos, la segmentación y los canales de distribución que utilizará para llegar a los clientes.

\section{Estrategia Funcional}

Las estrategias funcionales se basan en desarrollar las actividades principales de la Cadena de Valor de la empresa.

Se plantearán algunas estrategias con el fin de desarrollar la eficiencia y calidad superior de la empresa.

\section{Eficiencia superior}

- Continuar desarrollando economías de escala y adaptar la Cadena de Suministro al país donde se realizará la expansión de mercado. 
- Implementar el modelo Just In Time con el fin de reducir inventarios y trabajar la producción en base a la demanda de los diferentes mercados en vez de enfocarte solamente en la oferta. La empresa debe buscar el balance entre el modelo "push" y "pull”.

- Descentralizar la producción del continente asiático con el fin de acercar su fabricación a los diferentes mercados que atiende. Si desarrolla esta habilidad la empresa tendrá la capacidad de que su oferta llegue a todos sus puntos de venta en un tiempo estandarizado.

- Promover el desarrollo de una Cadena de Suministro sostenible con el objetivo de causar un impacto positivo en el medioambiente.

\section{$\underline{\text { Calidad superior }}$}

- Incentivar a toda la empresa a trabajar en base a una gestión de calidad. Involucrar desde la dirección hasta el personal de rangos bajos y hacerles entender la importancia de los programas de calidad. La empresa debe asumir la responsabilidad de capacitar a su personal en este tema.

- Desarrollar herramientas de calidad que le permitan a la empresa mapear los problemas que van surgiendo como el Diagrama Causa-Efecto, Diagrama de Flujo o Pareto.

- Promover el desarrollo de proveedores, es decir, actuar como un consultor de mejoramiento continuo. Se debe seleccionar a los proveedores más críticos y que más impacto tengan en nuestra cadena de suministro y analizar criterios como actitud, nivel de calidad, capacidad, experiencia, entregas a tiempo, entregas a todas las localidades, estabilidad financiera, motivación, entre otras.

\section{Estrategia global}

Para definir la estrategia global a aplicarse, se analizará el cuadro de estrategias básicas. 
Figura 2.4

Cuatro estrategias básicas

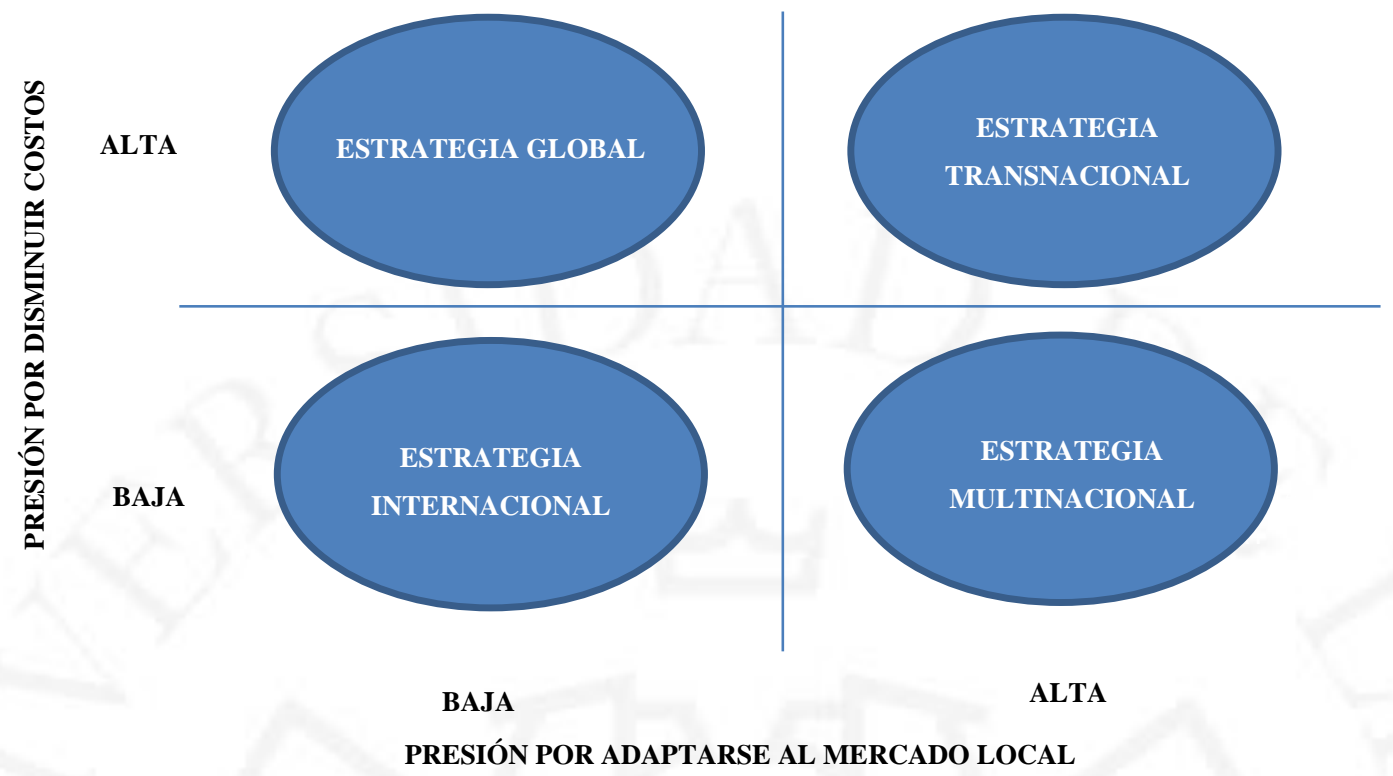

Fuente: Hill, C. W. L. y Jones, G. R. (2009).

Elaboración propia

En el caso de Fast Retailing, se observa que la estrategia que se adapta mejor a su negocio es una Estrategia de Estandarización Global.

"Las compañías que aplican una estrategia de estandarización global se enfocan en incrementar la rentabilidad mediante el aprovechamiento de las reducciones de costos que provienen de las economías de escala y de ubicación; es decir, su modelo de negocio se basa en la aplicación de una estrategia de costos bajos a escala global." (Hill y Jones, 2009, p. 279).

La presión que tiene la empresa por disminuir costos es alta debido al modelo de negocio que, si los costos de FR suben y los precios se mantienen bajos la utilidad de la empresa disminuiría considerablemente. Por el lado de la presión por adaptarse al mercado local es baja ya que los productos ofrecidos por FR son estándar. 


\section{CAPÍTULO III: IMPLEMENTACIÓN ESTRATÉGICA}

3.1 Evaluación del rediseño o no rediseño de la estructura organizacional de la empresa

La propuesta de diseño de estructura organizacional es una multidivisional. Con este tipo de organización, las UEN trabajan como unidades prácticamente autónomas desarrollando cada una sus operaciones.

Figura 3.1

Organigrama UNIQLO

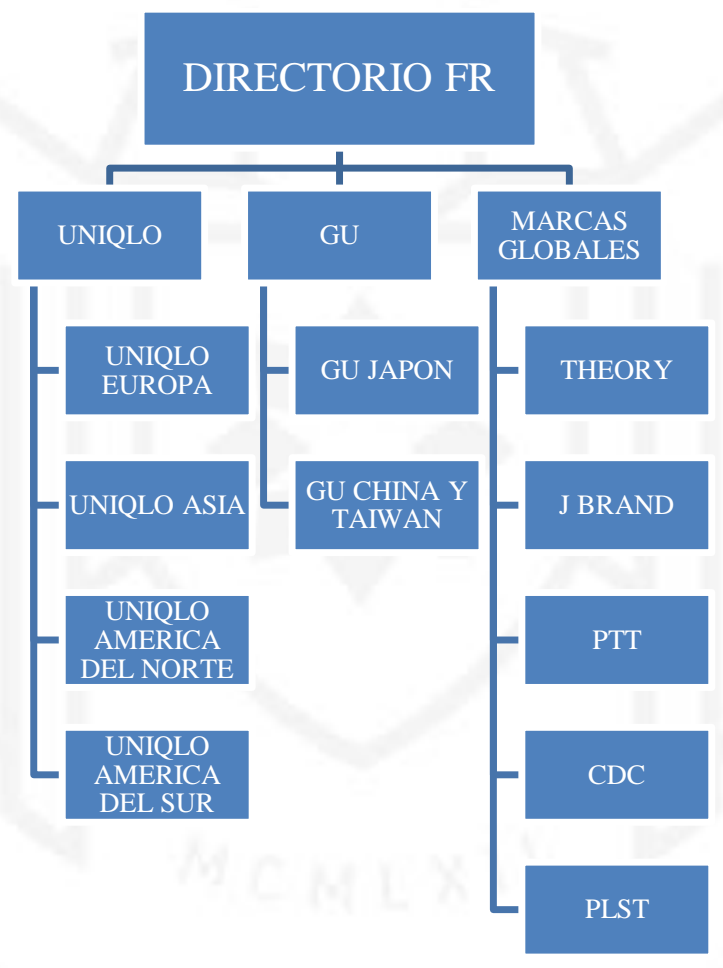

Elaboración propia

3.2 Propuesta de cambios para mejorar la implementación de estrategias en la empresa

Para mejorar la implementación de las estrategias de la empresa, el planeamiento debe comenzar desde cero. 
En primer lugar, se debe iniciar por la formulación lo cual involucra analizar el modelo de negocio, seguido de entender la misión, visión y valores de la empresa lo cual conlleva a un análisis PEST y de "Las 5 Fuerzas de Porter". Una vez se haya desarrollado el análisis de los factores internos y externos se realiza una matriz FODA la cual nos permitirá desarrollar estrategias funcionales, de negocios, globales y corporativas en base a los objetivos planteados por la organización. Dentro de esta planeación la empresa debe incluir a todas las jerarquías, desde los mandos bajos hasta la dirección, las personas que se encuentran en la base de la pirámide son las que viven el día a día de la empresa, por ende, conocen los problemas que se puedan estar generando y también las actividades que están sumando valor. Adicionalmente, la empresa también debe tomar en consideración a sus proveedores y a las fábricas con las cuales mantiene relaciones estrechas para comunicarles las estrategias planteadas y considerar el feedback propuesto por ellos en caso se tengan que hacer una reformulación.

En resumen, los cambios propuestos para la etapa de la formulación son los siguientes:

- Desarrollar un análisis interno y externo de la empresa.

- Incluir a los mandos bajos y medios.

- Incluir a los proveedores y fábricas con las cuales se mantienen relaciones estrechas.

Después de la formulación, pasamos a la implementación de las estrategias las cuales deben ser comunicadas desde la punta de la pirámide, es decir desde los directores, hasta los mandos bajos. Con el fin de que la implementación sea exitosa, se debe analizar si la estructura organizacional es adecuada para soportar las estrategias planteadas, de lo contrario, ver una reestructuración. También, se debe reforzar la cultura organizacional que Franklin Fincowsky (2014) la define como: “Conjunto de creencias, actitudes, valores, hábitos, costumbres y formas de hacer las cosas que comparten los miembros de una sociedad en función de su contexto social y valores que la sustentan” (p. 5). Si la cultura organizacional está alineada con la empresa todo el personal se involucrará en el desarrollo de las estrategias, de lo contrario, debe haber un reforzamiento. Por último, se deben diseñar controles para medir los resultados de las estrategias implementadas como indicadores relacionados a recursos humanos, marketing, producción, entre otros. 
Los cambios propuestos para la implementación de las estrategias son los siguientes:

- Todo el personal debe estar involucrado en la implementación de las estrategias

- Analizar la cultura organizacional

- Implementar controles para medir resultados 


\section{CAPÍTULO IV: CONTROL ESTRATÉGICO}

\subsection{Diseño de un Mapa Estratégico de Control para la empresa}

Figura 4.1

Mapa Estratégico de Control

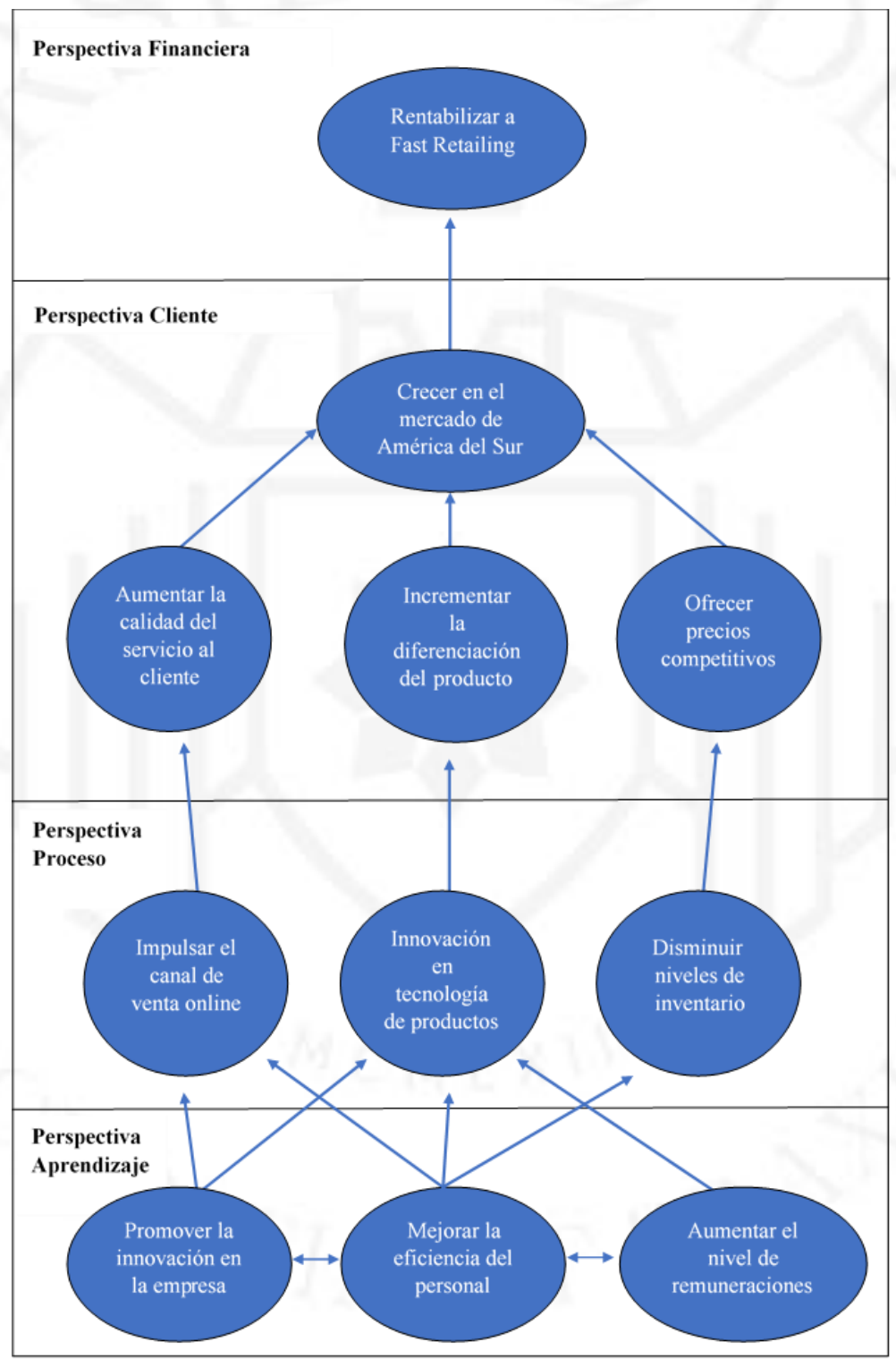

Fuente: Kaplan, R. S., y Norton, D. P. (2009).

Elaboración propia 


\subsection{Desarrollo de un Cuadro de Mando Integral con un mínimo de 10 índices de gestión}

Tabla 4.1

Cuadro de Mando Integral

\begin{tabular}{|c|c|c|}
\hline \multirow{2}{*}{$\begin{array}{l}\text { PERSPECTIVA } \\
\text { FINANCIERA }\end{array}$} & Rentabilidad sobre ventas & Utilidad Neta / Ventas Netas x 100 \\
\hline & Incremento de utilidad neta & $\begin{array}{l}\text { Utilidad neta } 2018 \text { - Utilidad neta } \\
\text { actual / Utilidad neta pasada } * 100\end{array}$ \\
\hline \multirow{3}{*}{$\begin{array}{l}\text { PERSPECTIVA } \\
\text { CLIENTE }\end{array}$} & $\begin{array}{lll}\begin{array}{l}\text { Satisfacción } \\
\text { cliente }\end{array} & \text { mensual del } \\
\end{array}$ & Clientes satisfechos / Clientes totales \\
\hline & Atracción de nuevos clientes & \# Clientes nuevos / \# clientes totales \\
\hline & Diferenciación del producto & $\begin{array}{l}\text { Atributos de tu producto vs. Atributos } \\
\text { de la competencia }\end{array}$ \\
\hline \multirow{3}{*}{$\begin{array}{l}\text { PERSPECTIVA } \\
\text { PROCESO }\end{array}$} & Ventas online diarias & $\begin{array}{l}\text { \# Ventas online diarias / \# Ventas } \\
\text { diarias }\end{array}$ \\
\hline & $\begin{array}{l}\text { Crecimiento de inversión en } \\
\text { innovación }\end{array}$ & $\begin{array}{l}\text { Presupuesto asignado a innovación / } \\
\text { Presupuesto total } * 100\end{array}$ \\
\hline & $\begin{array}{l}\text { Aumentar la rotación de } \\
\text { inventarios }\end{array}$ & $\begin{array}{l}\text { Costo de mercaderías vendidas } \\
\text { Inventario Promedio }\end{array}$ \\
\hline \multirow{5}{*}{$\begin{array}{l}\text { PERSPECTIVA } \\
\text { APRENDIZAJE }\end{array}$} & $\begin{array}{l}\text { Gastos de capacitación por } \\
\text { empleado }\end{array}$ & Gastos de capacitación / Gastos totales \\
\hline & Ingresos por trabajador & $\begin{array}{l}\text { Ingresos totales / Número de } \\
\text { trabajadores }\end{array}$ \\
\hline & $\begin{array}{l}\text { Satisfacción del ambiente } \\
\text { laboral }\end{array}$ & $\begin{array}{l}\text { Número de trabajadores satisfechos } \\
\text { con el ambiente laboral / Número de } \\
\text { trabajadores }\end{array}$ \\
\hline & $\begin{array}{l}\text { Innovaciones propuestas por } \\
\text { los trabajadores de productos } \\
\text { o procesos }\end{array}$ & $\begin{array}{l}\text { Innovaciones propuestas } \\
\text { Innovaciones totales }\end{array}$ \\
\hline & \begin{tabular}{|l}
$\begin{array}{l}\text { Incrementar el nivel de } \\
\text { remuneraciones }\end{array}$ \\
\end{tabular} & Gasto total de personal / \# trabajadores \\
\hline
\end{tabular}

Fuente: Kaplan, R. S., y Norton, D. P. (2009).

Elaboración propia 
Se utilizará la herramienta del Cuadro de Mando Integral o Balance Score Card con el fin de enlazar las estrategias y objetivos planteados con el desempeño y los resultados de la organización.

Las 4 perspectivas que se desarrollan en este sistema son las siguientes: Aprendizaje, proceso, cliente y financiera.

En primer lugar, se desarrollará la perspectiva del aprendizaje que promueve el desarrollo y crecimiento del capital humano de la empresa. Es importante que la empresa invierta en el progreso de las habilidades blandas y duras de su personal ya que éste se debe encontrar capacitado y motivado para que la implementación de las estrategias y el cumplimiento de los objetivos sean exitosos. En esta perspectiva se plantea los siguientes indicadores:

- Gastos de capacitación por empleado

- Ingresos por trabajador

- Satisfacción del ambiente laboral

- Nivel de remuneraciones

Con estos 4 indicadores se abarcará 3 importantes dimensiones las cuales son la productividad, retención y satisfacción de los trabajadores.

En segundo lugar, se detallará las perspectivas del proceso, desarrollando algunos que se consideran importantes y que están relacionados a la cadena de valor de la compañía. Las principales estrategias u objetivos involucrados están asociados a iniciar procesos de innovación de productos o servicios, analizar si se están cumpliendo con los requerimientos de los clientes, medir el servicio de posventa, entre otros.

Los indicadores planteados para esta perspectiva son los siguientes:

- Impulsar el canal de venta online

- Innovación en tecnología de productos y servicios

- Disminuir los niveles de inventario

Éstos 3 indicadores le permitirán a la empresa aumentar sus canales de venta, ofrecer productos con una tecnología diferenciada o impactar en la experiencia de compra del cliente, y reducir costos en base a una mejor gestión de inventarios. 
Prosiguiendo con las perspectivas, en tercer lugar, se encuentran las del cliente y están relacionadas con la satisfacción, fidelización y retención de estos. Anteriormente, las empresas priorizaban la generación de ingresos y el mejoramiento interno de la empresa sobre las necesidades de los clientes, pero ahora el énfasis se da al revés.

Los indicadores para medir esta perspectiva son:

- $\quad$ Satisfacción del cliente

- $\quad$ Atracción de nuevos clientes

Esto le permitirá a la empresa fidelizar a los clientes que ya han comprado los productos anteriormente, es decir, retenerlos, y aumentar la participación de mercado con el incremento de nuevos clientes.

Por último, la perspectiva financiera, que es en la cual impactan todas las anteriores. Todas las perspectivas se enlazan para causar un resultado financiero que puede terminar siendo negativo o positivo. Lo que se busca es el crecimiento de la rentabilidad del negocio, por lo cual se han propuesto dos indicadores:

- Rentabilidad sobre ventas

- Incremento de la utilidad neta 


\section{CONCLUSIONES}

Para empezar con el análisis, se ha desarrollado el diagnóstico estratégico, en el ámbito interno y externo, de la compañía.

En referencia al diagnóstico interno, se determina que la gestión interna de la empresa se desarrolla de manera positiva ya que las fortalezas son superiores a las debilidades. Estas últimas se deberán considerar como puntos a ser mejorados a través de acciones y estrategias. Asimismo, se identificó que la UEN con mayor presencia y con mejores cualidades es UNIQLO, logrando una su ventaja competitiva sostenida en la eficiencia superior, la superior capacidad de atención al cliente y la calidad superior.

Posteriormente, se procedió a evaluar los factores externos logrando detectar las oportunidades y amenazas de la situación actual del Perú. Como conclusión se obtuvo que FR tiene la capacidad para aprovechar las oportunidades y defenderse ante las amenazas. Por más de que el escenario político sea incierto y complicado en estos momentos, el escenario económico, social y tecnológico demuestran una tendencia positiva que se adapta al modelo de negocio de Fast Retailing, en especial al de UNIQLO.

Con el fin de proponer estrategias y objetivos en base al escenario actual de la empresa y, se realizó una matriz FODA facilitando cruzar las fortalezas y debilidades con las oportunidades y amenazas. Asimismo, se desarrolló un Cuadro de Mando Integral para que la empresa pueda controlar la implementación de las estrategias y enlazarlas entre las perspectivas. 


\section{RECOMENDACIONES}

La recomendación principal es que Fast Retailing comience a expandir sus operaciones a América del Sur considerando el crecimiento del retail y del desempeño positivo de las fast fashion hasta el momento. El desarrollo de mercado lo debe iniciar con su marca principal, UNIQLO, ya que ésta tiene un posicionamiento global y es la que mejor puede adaptar su modelo de negocio a los requerimientos del consumidor peruano, principalmente porque la tendencia de hoy es ofrecer productos de calidad a precios accesibles. Adicionalmente, debe aprovechar el crecimiento del canal de ventas online, el cual ninguno de sus competidores directos ha desarrollado aún en el Perú y no solamente posicionarse en Lima, sino también en provincia. 


\section{REFERENCIAS BIBLIOGRÁFICAS}

Coyle, J. J. (2013). Administración de la cadena de suministro: Una perspectiva

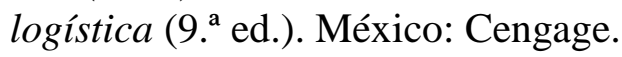

Franklin Fincowsky, E.B. (2014). Organización de empresas (4. ${ }^{\text {a }}$ ed.). México, D.F: McGraw-Hill Interamericana

Hill, C. W. L. y Jones, G. R. (2009). Administración Estratégica (8. a ed.). México D.F.: McGraw-Hill

Ismail, S., Malone, M. S., y van Geest, Y. (2016). Organizaciones exponenciales. Madrid: Bubok Publishing S.L.

Kaplan, R. S., y Norton, D. P. (2009). El cuadro de mando integral: The balanced Scorecard (3. ${ }^{\mathrm{a}}$ ed.). Barcelona: Gestión 2000

Louffat, E. (2015). Administración: Fundamentos del proceso administrativo (4. ${ }^{\mathrm{a}}$ ed.). México D.F.: CENGAGE Learning.

Lerma Kirchner, A. E. (2017). Desarrollo de productos: Una visión integral (5. $\left.{ }^{\mathrm{a}} \mathrm{ed}.\right)$. México D.F.: CENGAGE Learning

Porter, M. E. (2010). Ventaja competitiva: Creación y sostenibilidad de un rendimiento superior. Madrid: Pirámide.

Porter, M. E. (2015). Ventaja competitiva: Creación y sostenimiento de un desempeño superior (2. ${ }^{\mathrm{a}}$ ed.). México D.F.: Grupo Editorial Patria.

Parra Mesa, I. D. (2011). Innovación: Conceptos, proceso, mitos y realidades (2. ${ }^{a}$ ed.). Medellín: Universidad de Antioquia.

Fast Retailing CO., LTD. (2018). Customer Feedback and Product Improvements. Recuperado de https://www.fastretailing.com/eng/sustainability/products/customers.html 